\title{
Final Summary of
}

\section{“Interdisciplinary Study of Shewanella oneidensis MR-1's Metabolism \& Metal Reduction"}

This report describes the study supported by the Department of Energy (DOE)'s Genomes to Life grant DE-FG02-03ER63527 to PI Dr. E. Kolker at The BIATECH Institute (formerly BIATECH).

\section{Introduction}

The Shewanella Federation is a multi-investigator and cross-institutional consortium formed to characterize and model the biology of the metabolically versatile bacterium Shewanella oneidensis MR-1. This federation brings together the diversity of scientific expertise necessary to understand the biology of a microorganism at a wholesystem level. Information gathered from these systems-level investigations is aimed at modeling cellular networks to construct a computation model, predicting the biology of $S$. oneidensis MR-1 in general and its metabolic and metal-reduction capabilities in particular. The Shewanella Federation is one of the leading consortia within the DOE's Genomes-To-Life (GTL) Initiative.

As an integral part of the Shewanella Federation, our project focused primarily on analysis of different types of data produced by global high-throughput technologies, data integration of gene annotation, and gene and protein expression information, as well as on getting a better functional annotation of Shewanella genes. Specifically, four of our numerous major activities and achievements include the development of:

1. New statistical models for identification and expression proteomics, superior to currently available approaches (including our own earlier ones);

2. New approaches to improve gene annotations on the whole-organism scale;

3. New standards for annotation, transcriptomics and proteomics approaches;

4. New generalized approaches for data integration of gene annotation, gene and protein expression information.

Due to the space limitations, we describe in detail points 1 and 2 and briefly summarize 3 and 4. 


\section{Summary of Accomplishments}

\section{Statistical Models for Proteomics}

One of our principal achievements in proteomics analysis was the ability to effectively identify proteins in MS/MS analysis only identified by a single unique peptide; so called "one-hit-wonders" (Higdon et al 2007). To avoid false-positive protein identification, 2 or more unique peptides identified within a single protein are generally recommended. Still, in a typical high-throughput experiment, hundreds of proteins are identified only by a single peptide. We introduced a unique method for distinguishing between true and false identifications among single-hit proteins. The approach is based on randomized database searching and usage of logistic regression models with crossvalidation. This approach was implemented to analyze three bacterial samples, developed by several Shewanella Federation laboratories, and primarily based on the work by the Pacific Northwest National Laboratory and our own lab. Our original approach enables recovery $68-98 \%$ of the correct single-hit proteins with an error rate of $<2 \%$. This results in a $22-65 \%$ increase in number of identified proteins. Identifying true single-hit proteins will lead to discovering many crucial regulators, biomarkers and other low-abundance proteins.

Other advancements in proteomics analysis led to the development of our logistic identification of peptide sequences (LIPS) models for identifying peptides (Higdon et al 2004). These are statistically valid, customizable, and easy-to-use models for identifying peptides in high-throughput proteomics experiments. We have enhanced the use of randomized database searches to estimate false discovery rates for peptide and protein identifications (Higdon et al 2005). This approach has led to experiment-specific estimates of peptide identification probabilities to be used as thresholds for identification, and as a basis for estimating the false discovery rate for protein identification.

\section{Improving Genome Annotation}

One the most novel and significant achievements of this project was the collaborative integrative multi-institutional study to annotate hypothetical genes, led by our lab and published in PNAS (Kolker et al 2005). Similar to most other sequenced organisms, approximately $40 \%$ of the predicted ORFs in the S. oneidensis genome were 
annotated as uncharacterized hypothetical genes. We implemented an original integrative approach by using experimental and computational analyses to provide more detailed insight into gene function. Transcriptomic and proteomic analyses confidently identified 538 hypothetical genes as expressed in $S$. oneidensis cells both as mRNAs and proteins (33\% of all predicted hypothetical proteins). Publicly available analysis tools as well as databases and the expression data were applied to improve the annotation of these genes.

The annotation results were scored by using a unique seven-category schema that ranked both confidence and precision of the functional assignment. We were able to identify homologs for nearly all of these hypothetical proteins (97\%), but could confidently assign exact biochemical functions for only 16 proteins (category 1; 3\%). Altogether, computational and experimental evidence provided functional assignments or insights for 240 more genes (categories 2-5; 45\%). These functional annotations advance our understanding of genes involved in vital cellular processes, including energy conversion, ion transport, secondary metabolism, and signal transduction. We showed that this integrative approach offers a valuable means to undertake the enormous challenge of characterizing the rapidly growing number of hypothetical proteins with each newly sequenced genome.

\section{New standards}

All the above advancements were possible due to new standards developed for annotation, transcriptomics and proteomics approaches. New standards include both computational and experimental work, and were described in detail in 8 manuscripts, including the two most recently published in Nature Biotechnology (Nos. 24 and 25). Our work on the proteomics standards is currently supported by the NIH grant.

\section{Data Integration}

A fourth key area of development was in the integration of experimental highthroughput proteomics and genomics data with genome annotation data. This has resulted in a development of new integrative approaches in a general and new database system on S. oneidensis, called SODB. These approaches have been further generalized for use with multiple organisms and are currently supported by the NSF grant. 


\section{Conclusions}

Analysis of high-throughput data, the annotation of hypothetical proteins and the integration of this data are key to the success of modern biology. This project has made advances by overcoming bottlenecks in these areas that are crucial to understanding the biology of organisms such as S. oneidensis, and by enhancing our ability to deduce the complex networks and pathways responsible for the function and versatility of $S$. oneidensis and other organisms.

\section{References:}

1. Goodlett, D. R.; Keller, A.; Watts, J. D.; Newitt, R.; Yi, E. C.; Purvine, S.; Eng, J. K.; von Haller, P.; Aebersold, R.; Kolker, E., Differential stable isotope labeling of peptides for quantitation and de novo sequence derivation. Rapid Commun Mass Spectrom 2001, 15, (14), 1214-21.

2. Keller, A.; Nesvizhskii, A. I.; Kolker, E.; Aebersold, R., Empirical statistical model to estimate the accuracy of peptide identifications made by MS/MS and database search. Anal Chem 2002, 74, (20), 5383-92.

3. Keller, A.; Purvine, S.; Nesvizhskii, A. I.; Stolyar, S.; Goodlett, D. R.; Kolker, E., Experimental protein mixture for validating tandem mass spectral analysis. Omics 2002, 6, (2), 207-12.

4. Kolker, E.; Purvine, S.; Picone, A.; Cherny, T.; Akerley, B. J.; Munson, R. S., Jr.; Palsson, B. O.; Daines, D. A.; Smith, A. L., H. influenzae Consortium: integrative study of H. influenzaehuman interactions. Omics 2002, 6, (4), 341-8.

5. Tjaden, B.; Saxena, R. M.; Stolyar, S.; Haynor, D. R.; Kolker, E.; Rosenow, C., Transcriptome analysis of Escherichia coli using high-density oligonucleotide probe arrays. Nucleic Acids Res 2002, 30, (17), 3732-8.

6. Tjaden, B.; Haynor, D. R.; Stolyar, S.; Rosenow, C.; Kolker, E., Identifying operons and untranslated regions of transcripts using Escherichia coli RNA expression analysis. Bioinformatics 2002, 18 Suppl 1, S337-44.

7. Kolker, E.; Purvine, S.; Galperin, M. Y.; Stolyar, S.; Goodlett, D. R.; Nesvizhskii, A. I.; Keller, A.; Xie, T.; Eng, J. K.; Yi, E.; Hood, L.; Picone, A. F.; Cherny, T.; Tjaden, B. C.; Siegel, A. F.; Reilly, T. J.; Makarova, K. S.; Palsson, B. O.; Smith, A. L., Initial proteome analysis of model microorganism Haemophilus influenzae strain Rd KW20. J Bacteriol 2003, 185, (15), 4593-602.

8. Nesvizhskii, A. I.; Keller, A.; Kolker, E.; Aebersold, R., A statistical model for identifying proteins by tandem mass spectrometry. Anal Chem 2003, 75, (17), 4646-58.

9. Higdon, R.; Kolker, N.; Picone, A.; van Belle, G.; Kolker, E., LIP index for peptide classification using MS/MS and SEQUEST search via logistic regression. Omics 2004, 8, (4), 357-69.

10. Holzman, T.; Kolker, E., Statistical analysis of global gene expression data: some practical considerations. Curr Opin Biotechnol 2004, 15, (1), 52-7. 
11. Kolker, E. S., Framing as a cultural resource in health social movements: funding activism and the breast cancer movement in the US 1990-1993. Sociol Health Illn 2004, 26, (6), 82044.

12. Kolker, E.; Makarova, K. S.; Shabalina, S.; Picone, A. F.; Purvine, S.; Holzman, T.; Cherny, T.; Armbruster, D.; Munson, R. S., Jr.; Kolesov, G.; Frishman, D.; Galperin, M. Y., Identification and functional analysis of 'hypothetical' genes expressed in Haemophilus influenzae. Nucleic Acids Res 2004, 32, (8), 2353-61.

13. Purvine, S.; Kolker, N.; Kolker, E., Spectral quality assessment for high-throughput tandem mass spectrometry proteomics. Omics 2004, 8, (3), 255-65.

14. Purvine, S.; Picone, A. F.; Kolker, E., Standard mixtures for proteome studies. Omics 2004, $8,(1), 79-92$.

15. Raghunathan, A.; Price, N. D.; Galperin, M. Y.; Makarova, K. S.; Purvine, S.; Picone, A. F.; Cherny, T.; Xie, T.; Reilly, T. J.; Munson, R., Jr.; Tyler, R. E.; Akerley, B. J.; Smith, A. L.; Palsson, B. O.; Kolker, E., In Silico Metabolic Model and Protein Expression of Haemophilus influenzae Strain Rd KW20 in Rich Medium. Omics 2004, 8, (1), 25-41.

16. Higdon, R.; Hogan, J. M.; Van Belle, G.; Kolker, E., Randomized sequence databases for tandem mass spectrometry peptide and protein identification. Omics 2005, 9, (4), 364-79.

17. Hogan, J. M.; Higdon, R.; Kolker, N.; Kolker, E., Charge state estimation for tandem mass spectrometry proteomics. Omics 2005, 9, (3), 233-50.

18. Kolker, E.; Picone, A. F.; Galperin, M. Y.; Romine, M. F.; Higdon, R.; Makarova, K. S.; Kolker, N.; Anderson, G. A.; Qiu, X.; Auberry, K. J.; Babnigg, G.; Beliaev, A. S.; Edlefsen, P.; Elias, D. A.; Gorby, Y. A.; Holzman, T.; Klappenbach, J. A.; Konstantinidis, K. T.; Land, M. L.; Lipton, M. S.; McCue, L. A.; Monroe, M.; Pasa-Tolic, L.; Pinchuk, G.; Purvine, S.; Serres, M. H.; Tsapin, S.; Zakrajsek, B. A.; Zhu, W.; Zhou, J.; Larimer, F. W.; Lawrence, C. E.; Riley, M.; Collart, F. R.; Yates, J. R., 3rd; Smith, R. D.; Giometti, C. S.; Nealson, K. H.; Fredrickson, J. K.; Tiedje, J. M., Global profiling of Shewanella oneidensis MR-1: expression of hypothetical genes and improved functional annotations. Proc Natl Acad Sci U S A 2005, 102, (6), 2099-104.

19. Louie, B.; Mork, P.; Shaker, R.; Kolker, N.; Kolker, E.; Tarczy-Hornoch, P., Integration of data for gene annotation using the BioMediator system. AMIA Annu Symp Proc 2005, 1036.

20. Galperin, M. Y.; Kolker, E., New metrics for comparative genomics. Curr Opin Biotechnol 2006, 17, (5), 440-7.

21. Hogan, J. M.; Higdon, R.; Kolker, E., Experimental standards for high-throughput proteomics. Omics 2006, 10, (2), 152-7.

22. Kolker, E.; Higdon, R.; Hogan, J. M., Protein identification and expression analysis using mass spectrometry. Trends Microbiol 2006, 14, (5), 229-35.

23. Higdon, R.; Kolker, E., A predictive model for identifying proteins by a single peptide match. Bioinformatics 2007, 23, (3), 277-80.

24. Field D, Garrity G, Selengut J, ... Kolker E et al, Towards richer descriptions of our collection of genomes and metagenomes: the 'Minimum Information about a Genome Sequence' (MIGS) specification, Nature Biotechnology, 2007, in press.

25. Taylor C, Field D, Sansone A, ... Kolker E et al, Promoting Coherent Minimum Reporting Requirements for Biological and Biomedical Investigations: The MIBBI Project, Nature Biotechnology, 2007, in press. 